\title{
Statistical characteristics of Jakarta Composite Index (JCl) dynamics based on short term data represented in candles
}

\author{
Pasrun Adam ${ }^{1,2}$, La Gubu ${ }^{1}$, Edi Cahyono ${ }^{1,3, *}$ \\ ${ }^{1}$ Dept. Mathematics FMIPA Univ. Halu Oleo, Kendari, Indonesia \\ ${ }^{2}$ Graduate Program of Economics Univ. Halu Oleo, Kendari, Indonesia \\ ${ }^{3}$ Graduate Program Univ. Halu Oleo, Kendari, Indonesia
}

\section{Email address:}

edi_cahyono@innov-center.org (E. Cahyono)

\section{To cite this article:}

Pasrun Adam, La Gubu, Edi Cahyono. Statistical Characteristics of Jakarta Composite Index (JCI) Dynamics based on Short Term Data Represented in Candles. International Journal of Economics, Finance and Management Sciences. Vol. 2, No. 2, 2014, pp. 138-142.

doi: $10.11648 /$ j.ijefm.20140202.14

\begin{abstract}
This paper presents the dynamics of Jakarta Composite Index (JCI) where the data were observed daily from January 2008 to October 2012. The data are presented in candle forms, as often used in online trading software. Statistical analysis on the average and the variance is applied on every month candle representations. The average and the standard deviation may vary on each candle, meaning that they depend on time. The average that depends on time indicates a trend of the dynamics. On the other hand, the average and the standard deviation yield the so-called probability density function (pdf) which depends on time called temporal-pdf ( $\mathrm{t}$-pdf). The trend and the probability of the dynamics of JCI are implicitly represented in the t-pdf. The t-pdf of the dynamics of JCI is the main concern of this paper. Understanding the t-pdf will help investors deal with the dynamics of JCI.
\end{abstract}

Keywords: Jakarta Composite Index, Jakarta Stock Exchange, Temporal Probability Density Function, Dynamic Trend

\section{Introduction}

Jakarta Composite Index (JCI) is an index of all stocks that trading Indonesia Stock Exchange (ISX), formerly known as Jakarta Stock Exchange (JSX). JCI was established in April 1983. On August 10, 1982 the base index was 100. Currently, as the industries grow and more industries sell their stocks on ISX, the index has reached over 4000 .

The dynamics of JCI indicates performance indicators of industries selling their stocks on ISX. Hence, the understanding of the dynamic 'behavior' is a need both from practical and theoretical points of views. From practical point of view, the dynamic behavior of JCI is important for investors in their investment portfolio. From theoretical point of view, such dynamics is still hard to predict, especially for high frequency data [12].

This challenges theoretical scientists, including mathematicians and physicists, to create linkages with the existing theories or to develop a new theory to explain such dynamics. Often, theorists apply or develop existing mathematical models for the dynamics. For example, in the case of Italian stock market, D'Amigo and Petriani [1] uses semi-Markov environment to model stock market, and shows that it performed better than simple Markov model.

The aim of this paper is to develop temporal probability density function (t-pdf) of the dynamics of JCI based on candle representation of the data. A t-pdf consists of a trend of the dynamics, and also the probability of the dynamics from its trend. Most analysis to predict such dynamics is usually based on the trend only.

\section{Literature Review}

From economic point of view, the dynamics of commodities, stocks, indexes, and currencies may indicate completely different behavior. From mathematical point of view, however, they share similarities, especially the change of the value over time. Therefore, we review all related dynamics of theirs.

Partly, the study on dynamics of stocks, commodities, indexes and currencies can be traced. Evans and Lyon [8] studied the effect of macro news on the exchange rates. 
Huang et al. [11] reported the dynamics for the case of United States dollar (USD) v.s. Hong Kong dollar (HKD). Bekiros and Diks [2] carried out a study on causal linkages of six currencies: Euro (EUR), Great Britain Pound (GBP), Japanese Yen (JPY), Swiss Frank (CHF), Australian Dollar (AUD) and Canadian Dollar (CAD) relative to USD. The results indicated that currency returns might exhibit asymmetries and statistically significant higher-order moments. Such asymmetries are also found in [9] for the case of Singaporean dollar (SUD) and South African rand (SAR).

Gadea, Kaabia and Sabaté in [10] studied the relationship among Italian, Spanish, and United Kingdom prices over the period of 1874-1998. They found that the price of differential dynamics was captured by deterministic trends in the period of 1940-1998. Krylova, Nikkinen and Vähämaä [13] examined the cross-dynamics of volatility term structure slopes implied by foreign exchange options. Their empirical findings demonstrated that a few principal components could explain a vast proportion of the variation in volatility term structure slopes across the major exchange rates. Muchnic, Bunde and Havlin [16] also studied volatility, but focused on the return of an investment on shares and exchange rates. Béreau, Villavicencio and Mignon [3] studied the nonlinear dynamics of the real exchange rate towards its behavioral equilibrium value. They found that the real exchange rate convergence process in the long-run was characterized by nonlinearities for emerging economies, whereas industrialized countries exhibited a linear pattern.

The study on the dynamics (i.e. the ups and downs) of exchange rates has also attracted research in physics which then introduced the so-called econo-physics. In econo-physics, asset dynamics is often modeled by continuous time random walk (CTRW). In physics, CTRW is used to model anomalous diffusion, where a cloud of particles spread at a rate different from the classical Brownian motion. A rather comprehensive review of the CTRW for asset dynamics can be found in [15].

The CTRW model has been applied for the movement of asset log-prices (see, among others, [14, 17]). In particular, Roberto et al. [17] conducted an empirical study of tick-by-tick trading data for General Electric (GE) stock during October 1999. They used a Chi-square test to show that the waiting times and the subsequent log returns were not independent. The data showed that long waiting times resulted in small returns, while very short waiting times in large returns.

For the case of the dynamics of asset value in general, [4] show that the trend and the probability density function (pdf) of the dynamics are related to the fundamental solution of a type of diffusion equation, following [7] for the derivation of the solution. For more complex dynamics involving two or more stocks, commodities, indexes or currencies, the dynamics may be related to the interactions of fundamental type solutions in nonlinear model as discussed in [6].

\section{Data and Method}

\subsection{Data}

The data were provided by Bursa Efek Indonesia (BEI, Indonesia Stock Exchange) presented in the website of Dunia Investasi [18]. The data were presented daily from January 2008 to October 2012. The data were not presented numerically, but in the form of candle stick representation (Fig. 1) as often used in trading software. The data, however, are available upon request, or can be accessed in the website.

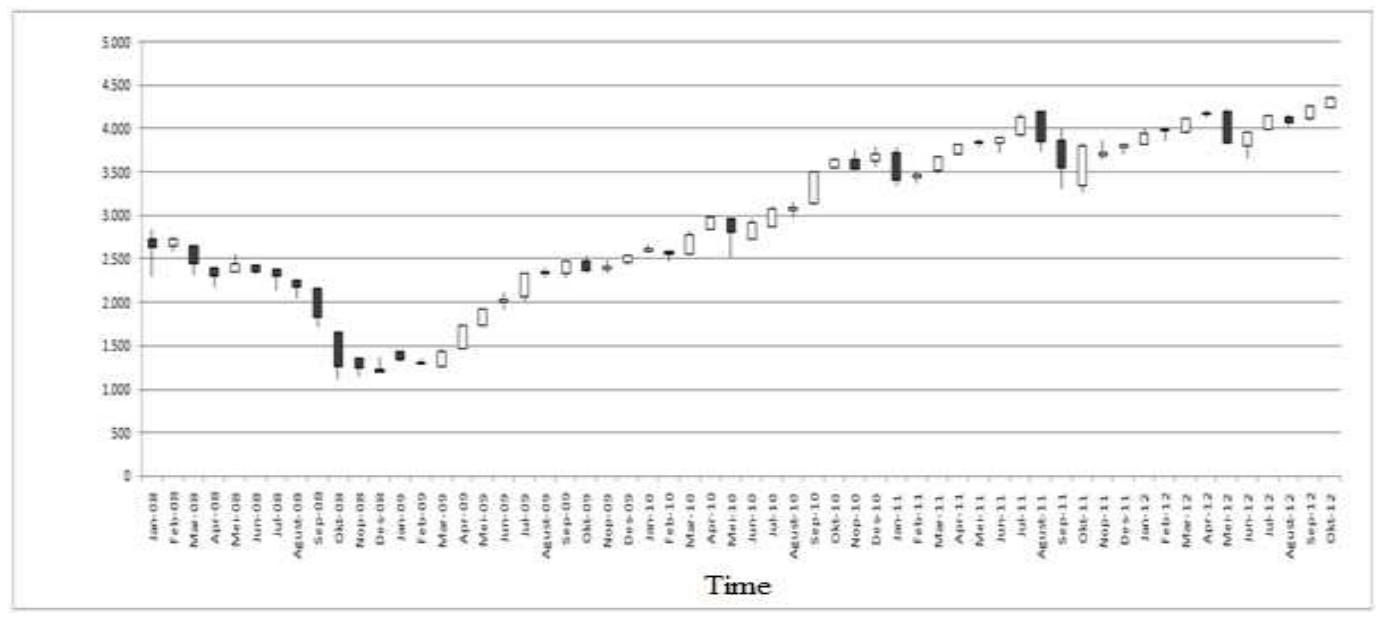

Figure 1. Candle stick representation of the daily data of the dynamics of JCI June 2008 to October 2012.

Such representation consists of dark and bright candles. Each candle represents information of opening data, closing data, highest data and lowest data during the time interval of the candles. Opening data are the first data recorded in that interval, and closing data are the last data recorded. A bright candle is a representation of the opening data being lower than the closing data. Dark candle represents the opposite. The upper wick candle (if any) represents the highest data in the time interval. Otherwise, the highest is either the opening or the closing data. Similarly, the lower 
wick candle (if any) represents the lowest data. Otherwise, the lowest is either the opening or the closing data.

Fig. 1 shows that the JCI was about 2,700 points in January 2008, but, dropped to about 1,200 in October 2008. This might be related to the global financial crisis which started in the United States (US). Starting in March 2009, however, it grew to be above 4,000 points in December 2012. Recently, it fell below 4,000, but this is not in the discussion of this paper.

\subsection{Methods}

The data are in the form of time series. In the candle stick representation, for every candle stick, the data were treated as steady state data, meaning that no longer did they depend on time. Hence, a candle stick represents the opening data, closing data, the highest data, and the lowest data.

\subsubsection{Average and Variance of Every Candle Stick}

For a candle stick, which contains monthly data we calculated the average and the variance. The average was calculated by applying the following formulae:

$$
\bar{x}=\frac{\sum_{i=1}^{n} x_{i}}{n}
$$

where $n$ is the number of data in the month. The number of data $n$ varies from 18 in March 2008 to 22 in October 2012.

On the other hand, the variance was calculated using the following formulae:

$$
\sigma^{2}=\frac{\sum_{i=1}^{n}\left(x_{i}-\bar{x}\right)}{n-1}
$$

\subsubsection{Temporal Average and Temporal Variance}

Note that the average and the variance may vary across the months, depending on time. Since we are interested in the dynamics of all time, we introduce temporal-average $(\mathrm{t}-\mathrm{a})$ and temporal-variance (t-v). The $\mathrm{t}-\mathrm{a}$, and $\mathrm{t}-\mathrm{v}$ will be computed by applying linear interpolation based on computed average and variance of all candle sticks. The t-a is often known as a trend of the dynamics.

Linear interpolation between two data of average (or variance) can be stated as follows: the first data (in month 1) is $y_{1}$ and the second data (in month 2) is $y_{2}$. Then, the average (or variance) at time- $t$ after the previous month but before month 1 , denoted by $y(t)$, is given in the following form:

$$
\frac{y(t)-y_{1}}{t}=y_{2}-y_{1}
$$

Graphically, this merely plots a line to connect the adjacent data points, which is well-known in software such as excel for plotting data.

\section{Results and Discussion}

Applying the formula for average and variance, we obtain the average and variance for all candle stick. The linear interpolations of the average and variance of a candle stick yields $\mathrm{t}-\mathrm{a}$ and $\mathrm{t}-\mathrm{v}$ which are plotted in Fig. 2 and Fig. 3, respectively. The average, as a function of time, is often called a trend. The variance indicates the spread of daily data in a month.

Starting in January 2008, the (monthly) trend of JCI decreased and reached its minimum points in November 2008 at 1,255 (Fig. 2). This minimum index was preceded by unstable trading of the ISX - the spread of day to day index are large, as indicated by the large value of variances in September and October 2008 (Fig. 3). The decrease of JCI in this period of time may be related to the 2008 global financial crisis, which started in the United States (US). It is not shown here, but at this month Indonesian rupiah (IDR) also depreciated relative to hard currencies, including US dollar (USD), in spite of the fact that at the same time US also experienced financial crisis. This means that the crisis had more impact on the IDR than USD. However, it is difficult to say that the crisis had more impact on Indonesia's economy than on US economy.

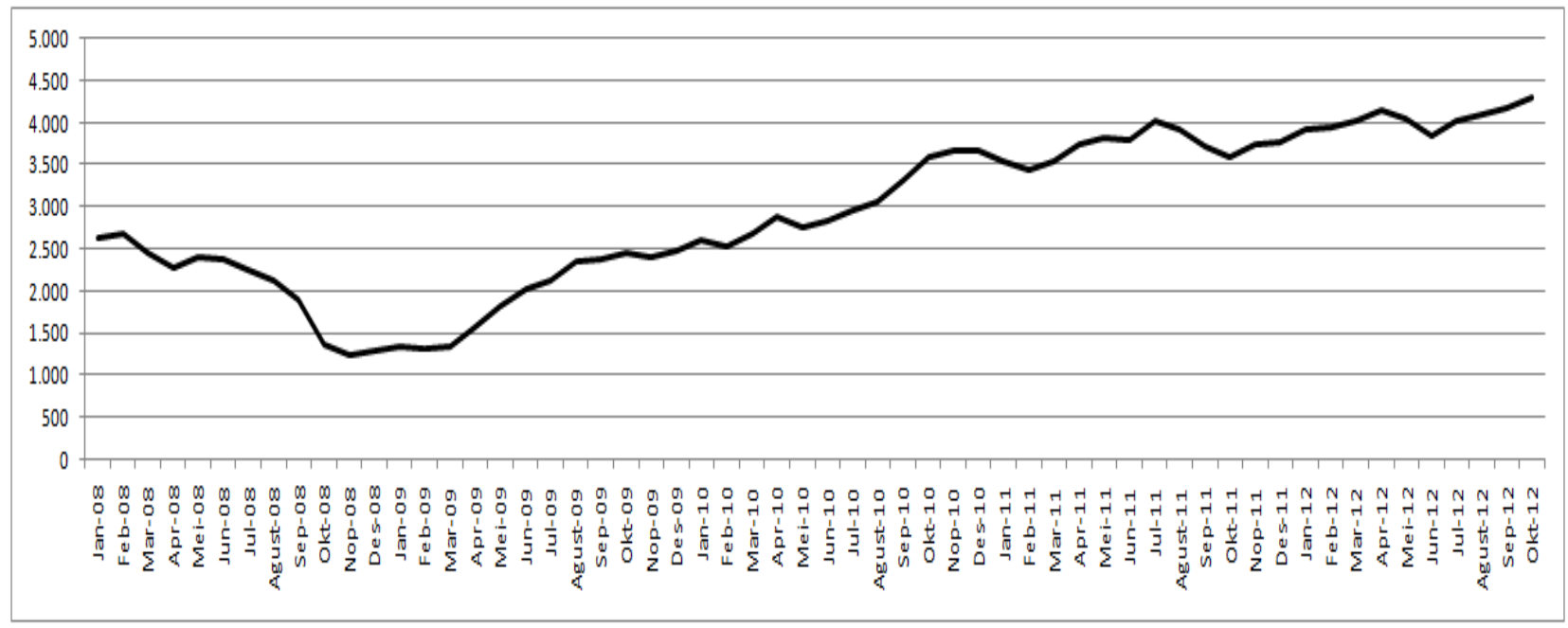

Figure 2. Linear interpolation of the average of candle sticks ( $t$-a) of the dynamics of JCI from January 2008 to October 2012. 


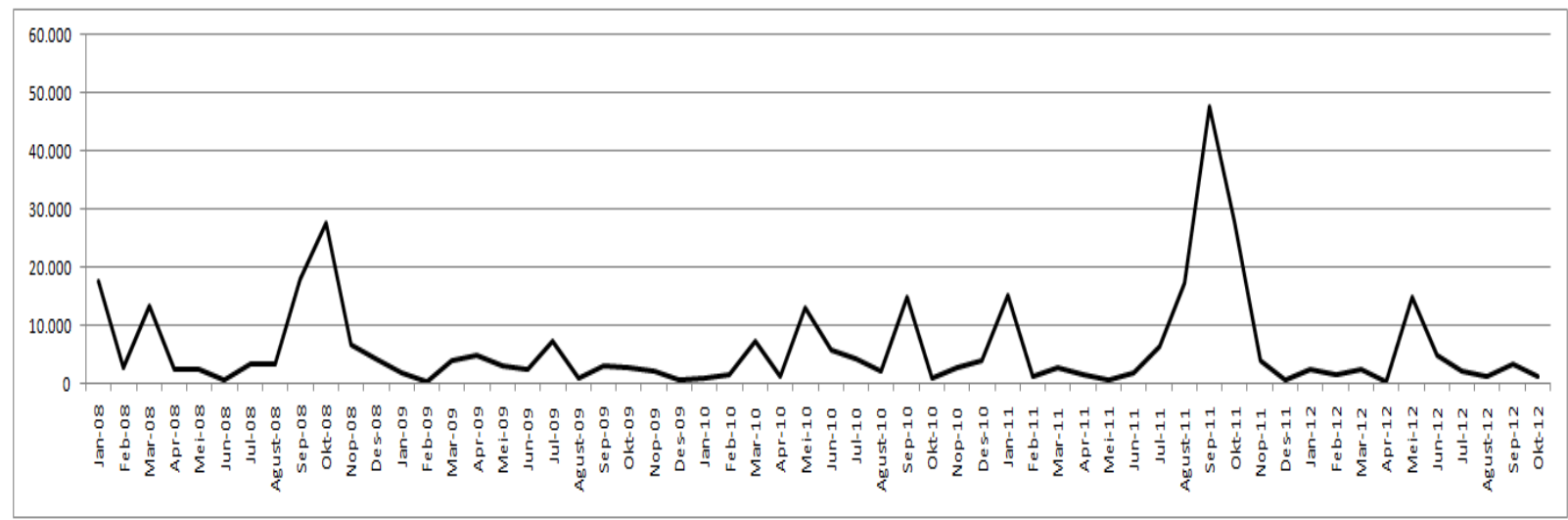

Figure 3. Linear interpolation of the variance of candle sticks (v-a) of the dynamics of JCI from January 2008 to October 2012.

In April 2009, JCI started to grow up, although there were some small fluctuations. One should note that from August to October 2011 the variances were large, and it reached the maximum level in September. Learning from what happened in September-October 2008, large variances preceded the decrease of JCI in the following month. In fact this was true, but this time JCI decreased shortly. In March 2012, JCI was back to the previous maximum value of June 2011.

Apart from economic point of view, the dynamics of JCI can be seen from statistical point of view or mathematical point of view. This may broaden our knowledge to understand the dynamics behavior which may benefit to preparing investment strategy. From statistical point of view, the dynamics of JCI can be written in the form of normal t-pdf

$$
f(x, t)=\frac{1}{\sqrt{2 \pi \sigma(t)}} \exp \left(\frac{x-\mu(t)}{2(\sigma(t))^{2}}\right)
$$

This is based on the dynamics whose data are presented in Fig. 1. Graphically, the temporal parameters are given in Fig. 2 and Fig. 3, respectively. The average as a function of time is often called as a trend. Note that for this mathematical notation $t$ is time (month), and January 2008 is zero acts as a reference of time. The t-pdf is also can be found by appling standard least square method as discussed in [5]. This method, however, is less used as a technical indicator in trading software.

\section{Conclusion}

A study on the dynamics of the Jakarta Composite Index (JCI) based on daily data from January 2008 to October 2012 is presented. The data is transfered in candle forms as often used in online derivative trading software. Statistical analysis on the average and the variance are applied on every monthly candle representations on which a unique average and a unique variance were yielded. This means that the average and the variance depend on time.

The average and the variance as functions of time are computed by applying a linear interpolation method. Substituting the average and the variance, which are functions of time, into normal probability density function (pdf), produces a temporal-pdf (t-pdf) of the dynamics of $\mathrm{JCI}$; the average as a function of time is often called a trend of the dynamics. Hence, t-pdf contains more information of the dynamics of JCI compared with the trend. The t-pdf is expected to yield better information to investors than the trend only.

\section{Acknowledgements}

This research is supported by Riset BOPTN Universitas Halu Oleo contract No. 176/PPK/Unhalu/IX/2012, Sept. 17, 2012.

\section{References}

[1] G. D’Amigo and F. Petroni, “A semi-Markov model for price returns," Physica A Statistical Mechanics and its Applications vol.391:20, pp.4867-4876, 2012.

[2] S.D. Bekiros and C.G.H. Diks, "The nonlinear relationship of exchange rates: Parametric and nonparametric causality testing," Journal of Macroeconomics vol. 30:4, pp. 1641-1650, 2008.

[3] S. Béreau, A.L. Villavicencio and V. Mignon, "Nonlinear adjustment of the real exchange rate towards its equilibrium value: A panel smooth transition error correction modeling," Economic Modelling vol. 27:1, pp. 404-416, 2010.

[4] E. Cahyono, J.R. Juliana and R. Raya, "Asset value dynamics and the fundamental solution of a modified heat equation," (in the $4^{\text {th }}$ International Conference on Mathematics and Statistics), Bandar Lampung, Indonesia, pp. 312-318, 2009.

[5] E. Cahyono, B. Sarita, P. Adam and F.P. Arisanty, "The trend and dynamics distribution of the Jakarta stock exchange (JSX) composite," International Journal of Economics and Finance Studies, vol. 4:2, pp. 77-85, 2012.

[6] E. Cahyono and Y. Soeharyadi, 2010. "On the interaction of Barenblatt's solution to the porous medium equation," International Journal of Mathematical Sciences and Engineering Applications, vol. 4:2, pp. 187-198, 2010.

[7] L.C. Evans, Partial Differential Equations. American Mathematical Society. Providence, Rhode Island, 2002. 
[8] M.D.D. Evans and R.K. Lyons, "How is macro news transmitted to exchange rates?" Journal of Financial Economics vol. 88:1, pp. 26-50, 2008.

[9] R. Emekter, B. Jirasakuldech and S.M. Snaith, "Nonlinear dynamics in foreign exchange excess returns: Tests of asymmetry," Journal of Multinational Financial Management vol. 19:3, pp. 179-192, 2009.

[10] M.D. Gadea, M.B. Kaabia and M. Sabaté, "Exchange rate regimes and prices: The cases of Italy, Spain and the United Kingdom (187-1998)," Journal of International Financial Markets, Institutions and Money, vol. 19:3, pp. 477-489, 2009.

[11] Y. Huang, S.N. Neftci and F. Guo, "Swap curve dynamics across markets: Case of US dollar versus HK dollar," Journal of International Financial Markets, Institutions and Money, vol. 18:1, pp. 79-93, 2008.

[12] T. Ito and K. Sato, "Exchange rate change and inflation in post-crisis Asian economies: Vector autoregression analysis of exchange rate pass-through. Journal of Money," Credit and Banking, vol. 40: 7, pp. 1407-1437, 2008.

[13] E. Krylova, J. Nikkinen and S. Vähämaä, “Cross-dynamics of votality term structures implied by foreign exchange options," Journal of Economics and Business, vol. 61:5, pp. 355-375, 2009.

[14] F. Mainardi, M. Roberto, R. Gorenflo and F. Scalas, "Fractional calculus and continuous time finance. II the waiting time distribution," Physica A: Statistical Mechanics and its Applications, vol. 287, pp. 468-481, 2000.

[15] M.M. Meerschaert and E. Scalas, "Couple continuous random walks in finance," Physica A: Statistical Mechanics and its Applications, vol. 370, pp. 114-118, 2006.

[16] L. Muchnik, A. Bunde and S. Havlin, "Long term memory in extreme returns of financial time series," Physica A: Statistical Mechanics and its Applications, vol. 388:19, pp. 4145-4150, 2009

[17] M. Roberto, E. Scalas and F. Mainardi, "Waiting-times and returns in high-frequency financial data: an empirical study," Physica A: Statistical Mechanics and its Applications, vol. 314, pp. 749-755, 2002.

[18] http://www.duniainvestasi.com/bei/prices/stock/COMPOSIT E (accessed December 14, 2012) 